\title{
Optimal Price and Freshness-Keeping Effort Level for a Reseller with Product Freshness and Quantity Deteriorating Simultaneously
}

\author{
Yan $\mathrm{SHI}^{1,}$ a , Wen-sheng YANG ${ }^{1, b}$ \\ ${ }^{1}$ School of Economics and Management, Nanjing University of Science and Technology, China \\ aemail:shiyandyx@163.com, bemail:wensheng_yang@163.com
}

\begin{abstract}
Keywords: fresh agricultural products; product freshness and quantity deterioration; pricing; freshness-keeping effort level.

Abstract. This paper introduces the freshness rate factor decays exponentially as time goes on to model a market demand function depends on sales price and freshness rate. At the same time, considering the dual influences exerted from the way freshness-keeping effort level of the reseller to the arrival rate and freshness, we've discussed the optimal price and freshness-keeping effort level on the basis of metamorphic inventory control theoretical model, and analyzed the influence of related parameters on the result of strategy.
\end{abstract}

\section{Introduction}

Fresh agricultural products, different from the ordinary perishable goods, it is the freshness that directly determines the product sales price and volume. With the rapid growth of economy, there has been an increasing awareness of food safety, which led to a higher requirement for the freshness of fresh agricultural products. It has important significance that making preservation technology investment on fresh agricultural products. Hsu et. al. [1] made an inventory model of fresh agricultural products with a fixed decay rate which could decline slowly by the preservation technology investment. Dye and Hsieh [2] use a time-varying rate of deterioration and partial backlogging for an inventory model. In [3], Lee and Dye Consider the influence of product inventory to the market demand. Lei Yang et. al. [4] consider quality and quantity loss of the agricultural products because of their own perishable, as well as anthropogenic factors in the process from the supplier to final consumers. Liu et. al. [5] formulate an inventory model for perishable foods with price-quality dependent demand. The objective is to determine a joint dynamic pricing and preservation technology investment strategy while maximizing the total profit from selling a given initial inventory of foods. Zhang et. al. [6] formulate a one-manufacturer-one-retailer supply chain model for deteriorating items with controllable deterioration rate and price-dependent demand, in which both players cooperatively invest in preservation technology to reduce deterioration.

Although the freshness of products as well as preservation technology investment are considered in the fresh agricultural product supply chain system in all the above studies, however, ignoring the effect of preservation technology investment to the freshness of products. In this paper, we consider the dual influences exerted from the way freshness-keeping effort level of the reseller to the arrival rate and freshness, formulate an inventory model for a fresh agricultural product to decide the optimal price and the level of freshness-keeping effort.

\section{Problem notations and assumptions}

In this paper, the reseller bought products from upstream distributor according to the market demand predicted and transportation to market itself. In order to ensure the freshness of the product, the reseller made preservation technology investment on transportation. This paper assumes that the level of freshness-keeping effort is $\mu, 0 \leq \mu \leq 1$. In the past literature, DAN Bin[7] uses an exponential function with downward slope as valuable loss with greenness, however, ignoring the effect of freshness-keeping effort level to the freshness of products. Therefore, this paper creates the 
product freshness is $\lambda=\left(\lambda_{0}+\mathrm{k}_{1} \mu\right) \mathrm{e}^{-\eta \mathrm{t}}, 0 \leq \mathrm{t} \leq \mathrm{T}$. This is a monotone decreasing function of $\mathrm{t}$ and conform to the reality, $\mathrm{T}$ is the trading periodicity, $0<\lambda_{0}<1$ is the initial freshness of productwhen the level of freshness-keeping effort is $0,0<\mathrm{k}_{1} \leq \frac{1-\lambda_{0}}{\mu}$ represents the sensitivity of freshness-keeping effort level to product freshness, $\eta$ is the time-elasticity of product freshness. Furthermore, there is an inevitable physical quantity deteriorating during transportation, taking into account the positive correlation between the effective supply rate and the freshness of the product, We assume that the product arrival rate is $\rho=A_{0}\left(\lambda_{0}+k_{1} \mu\right), 0<A_{0} \leq \frac{1}{\left(\lambda_{0}+k_{1} \mu\right)}$ is a constant; The demand rate is a bivar function of the retail price and the product freshness. For tractability, we assume $\mathrm{D}=\lambda(\mathrm{a}-\mathrm{bP})$, where $\mathrm{a}>0$ denotes the market potential and $\mathrm{b}>0$ represents the price sensitivity of demand. Moreover, $\mathrm{T}$ is the replenishment cycle(trading periodicity); $\mathrm{K}$ is the ordering cost per order of the reseller (Including transportation, loading and unloading as well as labor costs and so on); $\theta$ is the deterioration rate in the process of sales(Including spoilage and man-made losses); $\omega$ is the wholesale price; $h$ is the unit inventory holding cost per unit time; $Q$ is the initial inventory of product; $\mathrm{M}$ is the ordering quantity of the reseller; $\mathrm{C}$ is total cost of the rereseller; $\mathrm{I}(\mathrm{t})$ is the level of positive inventory at time; $\Pi_{\mathrm{r}}$ is the profit function of the reseller. We assume that the residual value is zero In consideration of the particularity of fresh agricultural products. Replenishment rate is instantaneously and lead time is zero. Shortages are not allowed.

\section{Model formulation}

According to the aforementioned notations and assumptions, we express inventory level of the reseller in the form of differential equations as: $\frac{\mathrm{dI}(\mathrm{t})}{\mathrm{dt}}=-\mathrm{D}-\theta \mathrm{I}(\mathrm{t}), 0 \leq \mathrm{t} \leq \mathrm{T}$.

Assume $I(T)=0$, we get the inventory level: $I(t)=\frac{\left(\lambda_{0}+k_{1} \mu\right)(a-b P)}{\theta-\eta}\left(e^{(\theta-\eta) T-\theta t}-e^{-\eta t}\right)$.

Hence, the initial inventory quantity $Q$ can be given by: $Q=\frac{\left(\lambda_{0}+k_{1} \mu\right)(a-b P)}{\theta-\eta}\left(e^{(\theta-\eta) \mathrm{T}}-1\right)$.

There is an inevitable quantity deteriorating $1-\rho$ during transportation, so the ordering quantity of the reseller can be obtained as $\mathrm{M}=\frac{\mathrm{Q}}{\rho}=\frac{(\mathrm{a}-\mathrm{bP})}{\mathrm{A}_{0}(\theta-\eta)}\left(\mathrm{e}^{(\theta-\eta) \mathrm{T}}-1\right)$

We define the cost of preservation investment is $S=\frac{1}{2} \mathrm{k}_{2} \mu^{2}$, where $\mathrm{k}_{2}>0$ represents the cost coefficient of investment. The function has been widely used in some literature, e.g. [8,9]. So the total profits of the reseller can be expressed as

$$
\begin{aligned}
& \Pi_{\mathrm{r}}=\pi-\mathrm{C}=\frac{\mathrm{P}\left(\lambda_{0}+\mathrm{k}_{1} \mu\right)(\mathrm{a}-\mathrm{bP}}{\eta}\left(1-\mathrm{e}^{-\eta \mathrm{T}}\right)-\frac{\omega(\mathrm{a}-\mathrm{bP})}{\mathrm{A}_{0}(\theta-\eta)}\left(\mathrm{e}^{(\theta-\eta) \mathrm{r}}-1\right) \\
& -\frac{\mathrm{h}\left(\lambda_{0}+\mathrm{k}_{1} \mu\right)(\mathrm{a}-\mathrm{bP}}{\theta-\eta}\left[\frac{1}{\theta} \mathrm{e}^{(\theta-\eta) \mathrm{r}}+\left(\frac{1}{\eta}-\frac{1}{\theta}\right) \mathrm{e}^{-\eta \mathrm{T}}-\frac{1}{\eta}\right]-\frac{1}{2} \mathrm{k}_{2} \mu^{2}-\mathrm{K}
\end{aligned}
$$

Taking the first-order partial derivatives of formula(2)with respect to $\mathrm{P}$ and $\mu$ and then making $\frac{\partial \Pi_{\mathrm{r}}}{\partial \mathrm{P}}=0, \frac{\partial \Pi_{\mathrm{r}}}{\partial \mu}=0$,we get the optimal price and freshness-keeping effort level:

$$
\mathrm{P}^{*}=\frac{\mathrm{a}}{2 \mathrm{~b}}+\frac{\mathrm{c \eta}}{2(\theta-\eta)\left(\lambda_{0}+\mathrm{k}_{1} \mu^{\mathrm{I}}\right)} \frac{\left(\mathrm{e}^{(\theta-\eta) \mathrm{T}}-1\right)}{\left(1-\mathrm{e}^{-\eta \mathrm{T}}\right)}+\frac{\eta \mathrm{h}}{2(\theta-\eta)} \frac{\left[\frac{1}{\theta} \mathrm{e}^{(\theta-\eta) \mathrm{T}}+\left(\frac{1}{\eta}-\frac{1}{\theta}\right) \mathrm{e}^{-\eta \mathrm{T}}-\frac{1}{\eta}\right]}{\left(1-\mathrm{e}^{-\eta \mathrm{T}}\right)}
$$




$$
\mu^{*}=\frac{k_{1} P^{I}\left(a-b P^{I}\right)\left(1-e^{-\eta T}\right)}{k_{2} \eta}-\frac{k_{1} h\left(a-b P^{I}\right)}{k_{2}(\theta-\eta)}\left[\frac{1}{\theta} e^{(\theta-\eta) T}+\left(\frac{1}{\eta}-\frac{1}{\theta}\right) e^{-\eta T}-\frac{1}{\eta}\right]
$$

Lemma1. The reseller's profits is concave in price when freshness-keeping effort lvele is fixed.

Proof.1 Taking the second-order partial derivatives of $\Pi_{r}$ with respect toc $\mathrm{P}$, It is obvious that $\frac{\partial^{2} \Pi_{\mathrm{r}}}{\partial \mathrm{P}^{2}}=-\frac{2 \mathrm{~b}\left(\lambda_{0}+\mathrm{k}_{1} \mu\right)}{\eta}\left(1-\mathrm{e}^{-\eta \mathrm{T}}\right)<0$, which impliesc that $\Pi_{\mathrm{r}}$ is concave in $\mathrm{P}$ for any $\mu$.

Lemma2. When price is fixed, reseller's profits is concave in freshness-keeping effort level .

Proof.2 Such as Proof.1, Taking the second-order partial derivatives of $\Pi_{\mathrm{r}}$ with respect to $\mu$, $\frac{\partial^{2} \Pi_{r}}{\partial \mu^{2}}=-k_{2}<0$, therefore, the profit of the reseller $\Pi_{r}$ is concave in $\mu$ for any $P$.

From Fig. 1, we obtain that $\Pi_{\mathrm{r}}$ is concave function about $\mathrm{P}$ and $\mu$ and verified the optimality of the formula(3),(4).

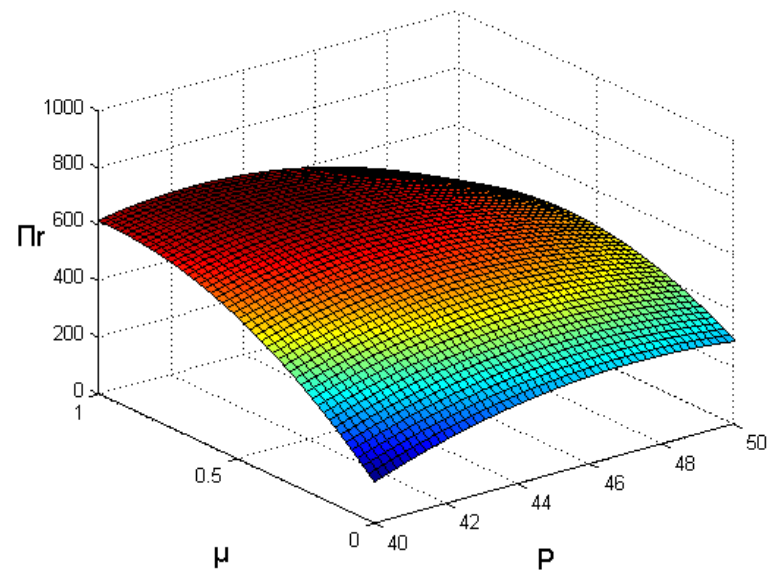

Fig.1. The total profit of the reseller

\section{Numerical analysis}

We set the following parameters for the benchmark case: $a=300, b=5, \theta=0.2, \eta=0.05$ $\lambda_{0}=0.65, \mathrm{k}_{1}=0.25, \mathrm{~A}_{0}=1, \omega=\$ 20, \mathrm{~h}=\$ 1, \mathrm{k}_{2}=\$ 1000, \mathrm{~K}=\$ 200, \mathrm{~T}=1$. Through Matlab software, we obtain that $\mathrm{P}=42.9748, \mu=0.8811, \mathrm{M}=91.8420$, and the total profit of the retail is 642.0803 .

we carry out sensitivity analysis with the price and time sensitivity. We vary one parameter once and keep others fixed, results are shown in Table 1-4.

Table 1. Sensitivity analysis with respect to b

\begin{tabular}{|c|c|c|c|c|}
\hline $\mathbf{b}$ & $\mathbf{P}$ & $\boldsymbol{\mu}$ & $\mathbf{M}$ & $\boldsymbol{\Pi}_{\mathbf{r}}$ \\
\hline 3.5 & 55.4123 & 1 & 114.4243 & 2121.2 \\
\hline 4.0 & 50.0551 & 1 & 107.6517 & 1485.0 \\
\hline 4.5 & 45.8885 & 1 & 100.8786 & 1005.5 \\
\hline 5 & 42.9748 & 0.8811 & 91.8420 & 642.0803 \\
\hline 5.5 & 40.7711 & 0.7434 & 81.7359 & 374.4666 \\
\hline 6 & 39.0112 & 0.6187 & 71.1346 & 177.2901 \\
\hline 6.5 & 37.6033 & 0.5024 & 59.9634 & 33.3228 \\
\hline
\end{tabular}

Table 2. Sensitivity analysis with respect to $\eta$

\begin{tabular}{|c|c|c|c|c|}
\hline $\boldsymbol{\eta}$ & $\mathbf{P}$ & $\boldsymbol{\mu}$ & $\mathbf{M}$ & $\boldsymbol{\Pi}_{\mathbf{r}}$ \\
\hline 0.05 & 42.9748 & 0.8811 & 91.8420 & 642.0803 \\
\hline 0.15 & 43.1204 & 0.8347 & 86.5436 & 587.5633 \\
\hline 0.25 & 43.2580 & 0.7915 & 81.6517 & 538.1320 \\
\hline 0.35 & 43.3876 & 0.7514 & 77.1325 & 493.2125 \\
\hline 0.45 & 43.5085 & 0.7140 & 72.9581 & 452.3039 \\
\hline 0.55 & 43.6227 & 0.6793 & 69.0916 & 414.9687 \\
\hline 0.65 & 43.7295 & 0.6469 & 65.5108 & 380.8240 \\
\hline
\end{tabular}


Table 3. Sensitivity analysis with respect to $\theta$

\begin{tabular}{|c|c|c|c|c|}
\hline $\boldsymbol{\theta}$ & $\mathbf{P}$ & $\boldsymbol{\mu}$ & $\mathbf{M}$ & $\boldsymbol{\Pi}_{\mathbf{r}}$ \\
\hline 0.02 & 41.7316 & 0.9184 & 89.9855 & 809.9027 \\
\hline 0.08 & 42.1249 & 0.9070 & 90.7296 & 754.8993 \\
\hline 0.14 & 42.5388 & 0.8946 & 91.3553 & 698.9345 \\
\hline 0.2 & 42.9748 & 0.8811 & 91.8420 & 642.0803 \\
\hline 0.26 & 43.4351 & 0.8663 & 92.1632 & 584.4259 \\
\hline 0.32 & 43.9216 & 0.8502 & 92.2913 & 526.0804 \\
\hline 0.38 & 44.4367 & 0.8325 & 92.1932 & 467.1760 \\
\hline
\end{tabular}

Table 4. Sensitivity analysis with respect to $\mathrm{k}_{1}$

\begin{tabular}{|c|c|c|c|l|}
\hline $\mathbf{k}_{\mathbf{1}}$ & $\mathbf{P}$ & $\boldsymbol{\mu}$ & $\mathbf{M}$ & \multicolumn{1}{|c|}{$\boldsymbol{\Pi}_{\mathbf{r}}$} \\
\hline 0.05 & 47.0923 & 0.1466 & 69.6303 & 323.3766 \\
\hline 0.1 & 46.5259 & 0.3023 & 72.6857 & 356.6176 \\
\hline 0.15 & 45.6018 & 0.4747 & 77.6707 & 416.4916 \\
\hline 0.2 & 44.3805 & 0.6681 & 84.2590 & 509.2245 \\
\hline 0.25 & 42.9748 & 0.8811 & 91.8420 & 642.0803 \\
\hline 0.3 & 41.9083 & 1 & 97.5952 & 816.4916 \\
\hline 0.35 & 41.3262 & 1 & 100.7893 & 1000.7 \\
\hline
\end{tabular}

According to Table 1., as the price-elasticity b decreases, $\mathrm{P}, \mu, \mathrm{M}, \Pi_{\mathrm{r}}$ decrease. That is because that the higher b means that people are more sensitive to product price, which lead to the reseller have to reduce the price to increase the market demand. In addition, the reseller cut total costs through decrease the freshness-keeping effort level to ensure its profits.

From Table 2., when $\eta$ is higher, $\mathrm{P}$ increase, $\mu, \mathrm{M}, \Pi_{\mathrm{r}}$ decrease.It's obvious that the faster freshness Decay of the product, the smaller market demand, while the product ordering quantity decrease. The reseller can get enough profits through increase price and decrease the freshness-keeping effort level.

Through Table 3., we find that as the deterioration rate in the process of sales $\theta$ increase, $\mathrm{M}, \Pi_{\mathrm{r}}$ increase. $\mathrm{P}, \mu$ decrease. Which shows that the reseller increaes the product ordering quantity to meet the needs of the market when $\theta$ is higher. Of course the reseller decrease the freshness-keeping effort level to cut its total costs.

As seen from Table 4., when $\mathrm{k}_{1}$ increase, $\mathrm{P}$ decrease, $\mu, \mathrm{M}, \Pi_{\mathrm{r}}$ increase. a higher sensitivity of freshness-keeping effort level to product freshness means that the cost of preservation investment decrease. Which urge the reseller improve its freshness-keeping effort level and decrease sales price to stimulate market demand for a higher profits.

\section{Conclusion}

This paper investigates the reseller's optimal price and freshness-keeping effort level with product freshness and quantity deteriorating Simultaneously and analyzed the influence of related parameters on the result of strategy. We find that the higher price-elasticity of market demand, deterioration rate in the process of sales,time-elasticity of product freshness, the lower profits. While a higher sensitivity of freshness-keeping effort level to product freshness can get more profits. Thus it has great significance to improve preservation technology in distribution logistics.

Not only saving large amounts of social resources but also improving the product freshness, enterprise performance and the living quality of people.

\section{References}

[1] Hsu,P.H.,Wee,H.M.Teng,H.M. :International Journal of Production Economics, Vol.124(2010), p. 388-394.

[2] Dye C Y,Hsieh T P. :European Journal of Operational Research,Vol.218(2012), p. 106-112.

[3] Lee Y P,Dye C Y :Computers\&Industrial Engineering,Vol.63(2012), p. 474-482.

[4] Lei Yang, $\mathrm{K}$ Chen, $\mathrm{G}$ Ma: International Journal of $\mathrm{u}$-and e-Service,Science and Technology, Vol.7(2014), p. 63-78. 
[5] Liu GW, Zhang JX, Tang WS. : Annals of Operations Research,Vol.226(2015), p. 397-416.

[6] Jianxiong Zhang,Guowei Liu,Qiao Zhang, Zhenyu Bai: Omega,Vol.56(2015), p. 37-49.

[7] DAN Bin, CHEN JunChinese Journal of Management Science, Vol.16(2008), p. 42-49.

[8] HE yong, YANG De-li, WU Qing-lie: Computer Integrated Manufacturing Systems, Vol.12(2006),p. 1865-1868.

[9] LUO Bing, FENG Hui, CHEN Xingqi: Science and Technology Management Research,Vol.10(2015), p. 222-226. 